\title{
The Impact Of The Internet On Albanian Teenagers
}

\author{
Bukurie Lila, PhD Candidate
}

European University of Tirana, Albania

doi: 10.19044/esj.2016.v12n5p226 URL:http://dx.doi.org/10.19044/esj.2016.v12n5p226

\begin{abstract}
The aim of this study is to look at the social impact that the internet has on the teenagers of "Arben Broci" school in Tirana. The study looks at the activities that teenagers engage themselves in on the internet, the hours they spend there, and the social influence that these activities have on them. By interviewing 100 people of different ages, some of which were interviewed in the high school, "Arben Broci” in Tirana, we have gathered qualitative and quantitative data through the use of a questionnaire. After the study, we concluded that the internet has both positive as well as negative impacts on socially isolated adolescents. We have seen that adolescents engage themselves in online chats through which they exchange data and information with people they do not know. This puts them at risk. In majority of the cases, they meet people whom they do not know their motives. The risk of child exposure to pornography and exploitation has increased along with the rise in internet use. The global nature of the internet also increases the child's risk of meeting a predator. According to Wolfe \& Higgings (2008), more attention has been given to online solicitation of sex from children. The positive social impact of the internet is that it creates an environment where teens can seek information needed for educational purposes. The study concludes that parents, teachers, and the government must be aware of the social impact of the internet on the lives of adolescents. Therefore, they must work together to minimize the harmful impacts of the internet on socially isolated students.
\end{abstract}

Keywords: Teenager, internet, school, impact, government

\section{Introduction}

Internet in Albania has spread very fast over the past 20 years. A lot of young people make use of the internet today. Also, old people have started to use the internet, especially for communicating with their relatives overseas.

The number of Facebook users in the country reached 1.1 million in 2013. According to the data published by Internet World Stat, in Albania, 
internet users have reached $60.1 \%$ in 2013.

Furthermore, it turns out that 1.8 million people used the internet last year. Hence, the number of Facebook users has nearly reached 1.1 million.

In using the internet, Albania has been ranked after Kosovo, Croatia, Bosnia, and Macedonia, surpassing Serbia, Montenegro, Bulgaria, and Romania.

During the period from 2010-2014, access to internet services provided by fixed and mobile networks was characterized by positive growth rates. Electronic Communications Authority announced in its recent report that in 2014, the number of subscribers in the fixed broadband access networks increased from 182.556 to 206.896 , or by 13 percent or more.

The city with the greatest internet penetration rate is Tirana, while the one with the lowest penetration is Dibra (about 2\%).

There are a great variety of information that can be accessed online. Though some are useful, others can be sometimes harmful. Some webpages may be harmful to students, encouraging them to take wrong actions or be isolated from the society. Basically, the information that students receive online are important because they have the power to influence the behavior and knowledge of students.

One positive impact of the internet on teenagers is innovation. The internet makes students more innovative and better able to do school research projects. Another positive example is knowledge. Students receive study materials online that help them meet the knowledge requirements of certain fields.

The purpose of this study is to determine the social impact of the internet on the isolation of adolescents, particularly for the high school students of "Arben Broci" in Tirana. This study will also help in providing additional information to help parents and the government.

"Arben Broci" school is interested in technological upgrades and promotes the growth of social groups at school. The school uses the social network "Facebook" to connect students with each other. Part of this research is to determine for what purpose high school students use social networks, and what kind of information is exchanged among themselves.

There are different social effects, which may have an impact on youths. Due to its virtual nature, the internet has the potential to affect the younger generations. The internet creates a social and cultural world where young people become part of simply by going online.

Parents are often not aware of the existence of social and cultural impacts of the internet on children. High school teens are active contributors in this cyber culture that is the internet. An example of culture that exists on the internet: students are often members of chat rooms involving teenagers that use nicknames to identify themselves. 
Han et al (2012) suggested that adolescents with low level of perceived family cohesion seemed to play games on the internet to compensate for striatal dopamine deficits caused by poor parental care during their early life (Bartels and Zeki, 2004; Pruessner et al., 2004; Aron et al, 2005). Improvement in the perception of family cohesion during family therapy could conceivably facilitate dopaminergic neurotransmission in the brain reward system and consequently reduce the level of craving for gaming online.

Given the social impact of the internet on students, parents and teachers should establish a regulatory internet access and monitor sites that are opened by teenagers or children. This is an immediate need in Albania.

Adolescents will spend more time online in the future than they currently do. The 'net will become more familiar and more appealing, and more people will be online, making it potentially more interesting. (Mortimer \& Larson, 2002).

\section{Establishment of the Problem}

The exponential increase of internet use has grown globally along with the problems and challenges. One of these challenges is that different types of information are made available to all those who have internet access. Gross et al. (2002) mentions in particular the fact that there is an uncertainty as to whether the information young people who have access to the internet obtain has a good influence on their development. This raises the need to recognize the effects of the internet on different groups of people. Our research is focused on the negative impact of the internet on teenagers, and especially in their social isolation. On the other hand, the internet also has a positive impact on young people, because students can use it to supplement the things taught in school.

\section{Research Questions}

What is the social impact of the internet on general secondary school "Arben Broci"?

This issue is divided into other sub-issues as follows:

Question 1

How does the internet influence the social lives of teenagers, and how do they interact with their family, friends, and teachers?

Question 2

What kind of information do the teens of "Arben Broci" require online?

Question 3

What websites do middle school students visit most often?

Question 4 
Are students involved in room conversations, and do they believe the information provided by their friends online?

Question 5

Do teenagers prefer to have real friends rather than virtual friends?

Question 6

How much time do students spend on the internet?

\section{Use of the Internet by our Survey}

Our survey confirmed our expectations in terms of attendance of the internet by youths. The internet is the most used and preferred tool by children and young people of this age. More than half of the respondents, mainly young men, said they use the internet several times a day, while the other half said they use it once a week. This high frequency of internet use testifies of the close relationship between youths of up to 32 years old and this type of media, and the impact that may be exercised in this regard. In fact, as was proved by the survey, the most frequent use of the internet was social networking, where only a small part of the respondents said they did not use these networks. Perhaps in some cases it can be said that virtual reality provided via the internet occupies more space in the life of this age group than everyday reality.

\section{The use of internet}
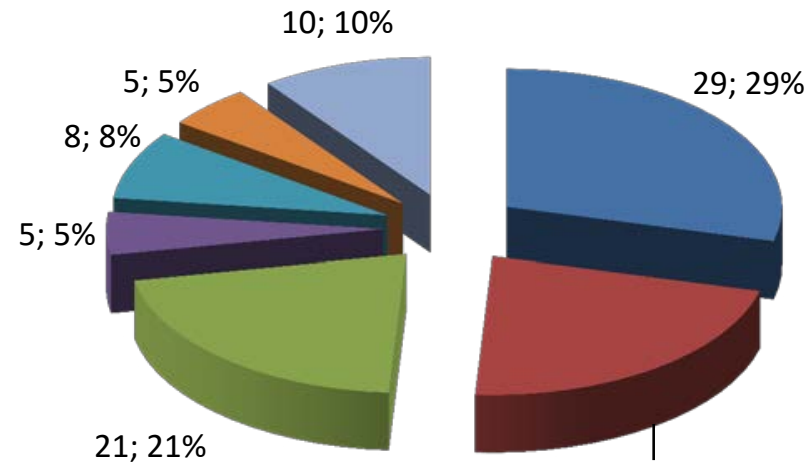

$15-20$ years

21-26 years

22-32 years

33-38 years

39-44 years

45 years and up

I don't use it 


\section{How often do you use the internet?}
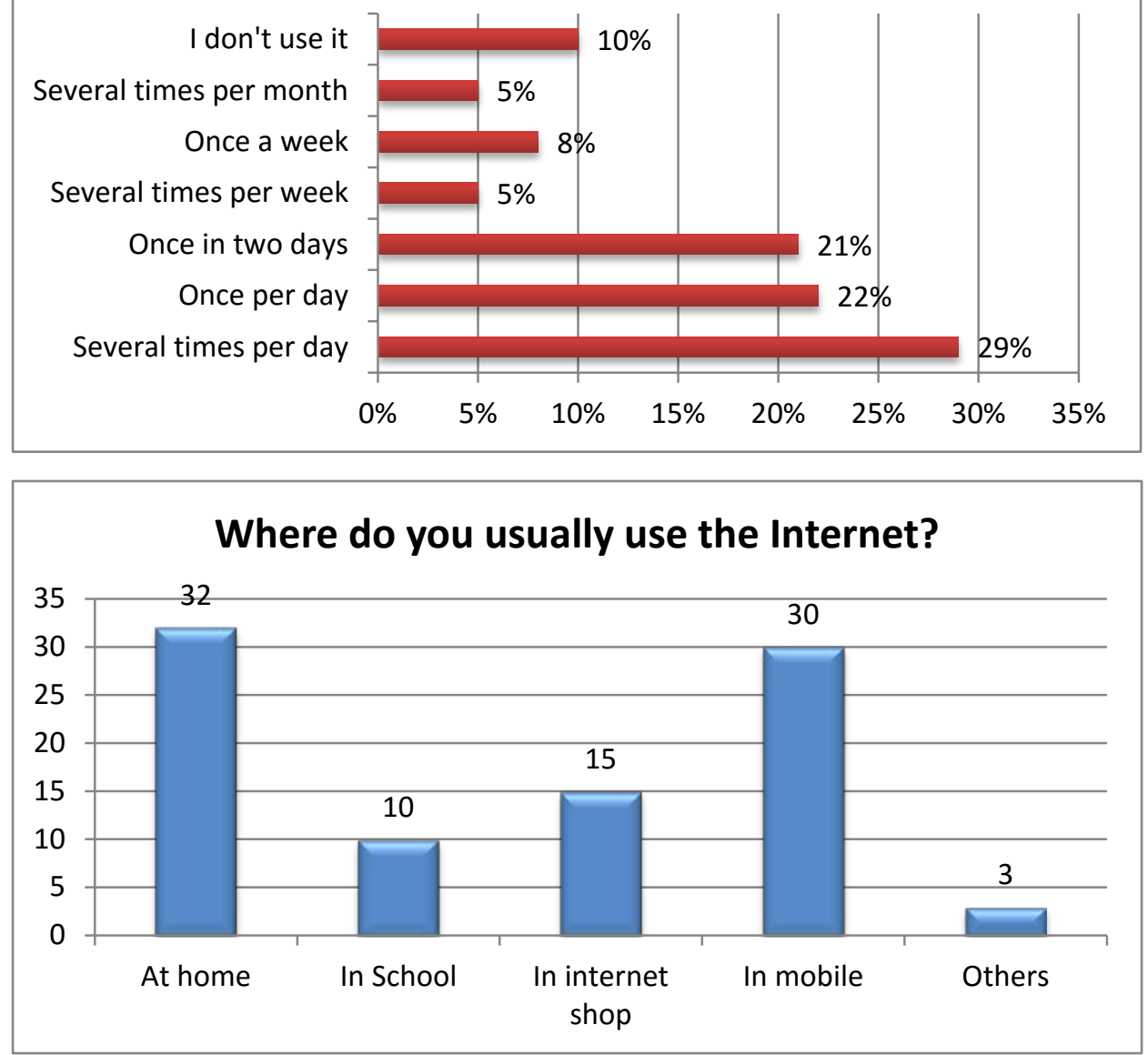

As can be seen, 29\% use the internet at least once a day. However, in fact, most use the internet several times a day. Meanwhile, only $10 \%$ said they do not use the internet. This extensive use of the internet is obviously connected with the growing importance that the internet has received during the last few years. In addition, the mass spread in the country, especially in the capital city, is another factor. So, when asked if they mainly used the internet, the vast majority of respondents said that they used the internet at home and on their mobile. This proves the easy access this age group has to this media. As expected, the majority of respondents use the internet for social media, which was significantly more popular than the other categories. However, there were few who use the internet for entertainment or information. Very few of the respondents said that they use the internet for other purposes, of which the most cited were reading books and getting the materials needed for various school projects. Given the wide use of the 
internet by this group to engage in social media activities, they were asked about the frequency and visibility of their profile, as well as how often they update their profile. While the vast majority said that they see it at least once a day, updating profiles were lower, but still substantial.

\section{How many times do you click social networks?}

45 years up, I don't know

39-44 years/ once per month

33-38 years/once per week

27-32 years/once per week

21-26 years/every day

$15-20$ years/every day

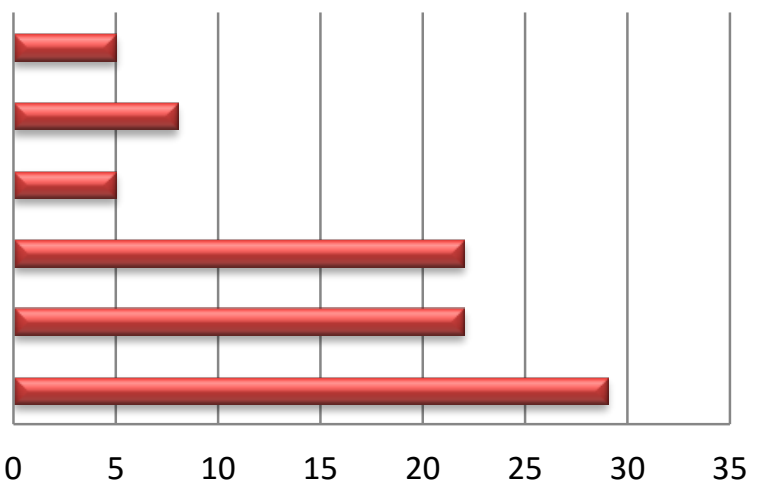

Seeing the high exposure of children and young people to the internet, especially social media, and the possibility of little control from adults in this regard, the respondents were asked if they had interference from adults in using the internet. Also, if they had problems with privacy on social media. $30 \%$ of respondents said they had interference by parents in using the internet. However, the interventions were mainly because of the amount of time they spent on the internet and not the purpose of using the internet. On the other hand, only $23 \%$ of respondents said that they had problems with privacy on social networks, while others said no.

\section{Conclusion}

In conclusion, I tried to explain the negative consequences of the internet to children. But anyway, these negative effects can be avoided. In recent years, there has been a growing interest in many countries to find ways to protect children from abuse that can come via the internet. An initiative has been taken by UNESCO, which was included later in the Convention on the Rights of the Child. This Convention, in its Article 17, imposes the obligation to take all necessary measures to protect children from information and electronic materials that could harm their welfare. However, to prevent the above risks it is essential to have a close cooperation between the government on one side and the authorities and parents on the other side. In this regard, much remains to be done in our country. For simplicity, we will divide it into two types of measures that can be taken: government measures and parental precautions. 


\section{Government Measures}

The government is responsible for the welfare of its citizens and in particular children. This is clearly expressed in our Constitution. The government has all the financial, human resources, and possibilities to take such measures. Relying on the practice of other countries, I think we should take these measures, as soon as possible, to adopt a special law to protect children online. A good model can be the law of the United States. This is a law that was passed in 2000. The law requires the placement of a filter on the internet access of children, especially at school or in the library. The law makes detailed adjustments as this filtering will be done, excluding what should not be allowed. We need to set up a special institution (watch-dog) to identify and monitor the websites that are visited mostly by Albanian children.

This institution will monitor the site, and if it notices violations, such as invasion of privacy, sexual harassment, etc., it would quickly adopt a strategy to protect children online. This strategy should be developed by specialists in the field, taking into account the behavior and living circumstances of children and their families. The government should, as soon as possible, embark on a public awareness campaign targeted at parents to raise their awareness of the dangers of the internet and how to have a safe internet use.

\section{Parental Precautions}

Part of the responsibility lies with the parents. They can do a lot for their children, in a manner that they do not fall prey of risks themselves. Parents can take the following measures. They must not place the computer in a child's room, but in a more open space; the salon will be better place. In this manner, the children will be afraid to visit certain websites. Thus, according to a study in the US, about $45 \%$ of adolescents enter the internet in school, in the library, in the house of friends or in an internet center.

Your child needs his freedom and may feel threatened. Make sure your child understands that when you see his/her screen, this action is not control, but a curiosity on your part. Ask what site your child is visiting; ask as if you do not know how to do something on the computer, etc. Talk about the dangers of navigating the internet. Build an open communication with your child and ask him to inform you if anyone tries to harass him on the internet. Ask them not to talk with strangers on social networks. Do not let the child stay online for a long time or late in the evening. Set up a convenient time when you are at home. Install a software on your computer that prevents children from accessing certain webpages. 


\section{References:}

Aron A. Fisher H, Mashek DJ, Strong G, Li H, Brown LL (2005). Reward, motivation, and emotion systems associated with early 0 stage intense romantic love. Journal of Neurophysiology 94 (327-337).

Aboujaoude, E., Starcevic, V., Mental Health in the digital age, Grave dangers, great promise. Oxford University press 2015.

Bartels A, Zeki S, (2004). The neural correlates of maternal and romantic love. Neuroimage 21; 1155-1166.

Internet Society, Global Internet Report 2015, found at, http://www.internetsociety.org/globalinternetreport/?gclid=CO7cleLvxMgCF YnVcgodAHQIcg on 15.10.2015

Gross, E. F., Juvonen, J., \& Gable, S. L. (2002). Internet use and well-being in adolescence. Journal of Social Issues, 58, 75 - 90

Mortimer J. T. and Larson R. W. The changing Adolescent Experience, Societal Trends and the Transition to Adulthood. Cambridge University Press, 2002)

Wolfe, S., Higgins, G. (2008). College students' punishment perceptions of online solicitation of children for sex. American Journal of Criminal Justice, 33(2), 193-208.

Pruessner JC. Champagne F, Meaney MJ, Dagher A (2000). Dopamine release in response to a psychological stress in humans and its relationship to early life maternal care: a positron emission temography study using raclopride. Journal of Neuroscience 24: 2825-2831. 